http://jmscr.igmpublication.org/home/

ISSN (e)-2347-176x ISSN (p) 2455-0450

crossref DOI: https://dx.doi.org/10.18535/jmscr/v7i11.144

Journal Of Medical Science And Clinical Research

\title{
Adnexal Torsion with Pregnancy: A Case Presentation
}

\author{
Authors

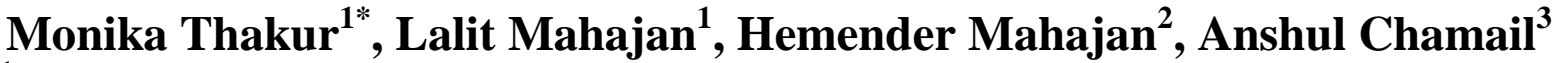 \\ ${ }^{1}$ Assistant Professor, Department of Obstetrics and Gynaecology, DYSPGMC Nahan 173001 \\ Himachal Pradesh, India \\ ${ }^{2}$ Assistant Professor, Department of Obstetrics and Gynaecology, SLBSGMC Mandi 175021 \\ Himachal Pradesh, India \\ ${ }^{3}$ Senior Resident, Department of Radiodiagnosis, DYSPGMC Nahan 173001'Himachal Pradesh, India \\ *Corresponding Author \\ Monika Thakur
}

Assistant Professor, Department of Obstetrics and Gynaecology, DYSPGMC Nahan 173001

Himachal Pradesh, India

\begin{abstract}
A 24-year-old women, presented with complaints of acute onset lower abdominal pain and vomiting. On clinical examination, a tender mass in the hypogastric region was palpable. Pelvic examination revealed the same mass felt anterior and through the right fornix, along with cervical motion tenderness. She missed her last periods and urine pregnancy test was weakly positive. Laboratory examination included a $\beta$-hCG assay with results of 39.8, haemoglobin level of 10.7, and white blood cell count of 9600. Ultrasonography revealed a cystic mass of size $9.9 \times 8.5 \mathrm{~cm}$ in the right adnexa along with presence of heterogenous area of $5 \times 8.2 \mathrm{~cm}$ with no vascularity with surrounding free fluid. A provisional diagnosis of chronic ectopic versus ovarian torsion was made as ultrasonographic findings were inconclusive of torsion. Exploratory laparotomy was done which revealed an enlarged, cyanotic and congested fallopian tube along with completely necrotic ovary on right side. Right salpingoopherectomy was performed because after untwisting of vascular pedicle there were no signs of reperfusion. The patient was discharged uneventfully on the fifth postoperative day. This case describes an interesting case of adnexal torsion along with pregnancy which was being misdiagnosed as chronic ectopic because of her positive urine pregnancy test and indeterminate ultrasound findings.
\end{abstract}

\section{Background}

Ovarian torsion has a prevalence of $2.7 \%$ among all cases of acute abdominal pain. It is the fifth most common gynaecological emergency. ${ }^{1}$ It is described as interruption of the blood flow to ovary due to partial or complete rotation of adnexa around its vascular axis. Adnexal torsion is a term which is inclusive of either ovary or fallopian tube or both. Concomitant ovarian and tubal torsion occurs in up to $67 \%$ of cases of adnexal torsion. ${ }^{2,3}$ Ischaemia which follows after torsion leads to necrosis of ovary and may necessitate oopherectomy if there is no viable tissue left during laparotomy/laparoscopy. Thus, timely diagnosis and an early intervention are required in cases of torsion. Also, this becomes more important in young females as extent of surgery has great implications for future fertility. This case 


\section{JMSCR Vol||07||Issue||11||Page 830-834||November}

report illustrates the misdiagnosis due to varied imaging features and positive urine pregnancy test. Thus, a high index of clinical suspicion is needed for timely intervention in such cases.

\section{Case Presentation}

A 24 year old nulliparous woman presented to emergency department with history of sudden onset right iliac fossa pain. The pain was severe in intensity and was associated with vomiting. She was recently married and was not using any contraception. On further enquiry she told that she missed her last periods and is 4 days overdue. A urine pregnancy test was done which came out to be weakly positive. In addition she had no history of fever, no urinary complaints and no gastrointestinal symptoms. She had no past history of sexually transmitted diseases. She had an history of ovarian cyst for which she did not sought any treatment.

On examination her vitals were stable and general examination was unremarkable. On abdominal examination, an ovoid mass was identified in the hypogastric region extending to the right iliac fossa which was tender to touch. Pelvic examination revealed the same mass which was felt mainly through anterior and right fornix. The uterus was not felt separately felt from the mass.

Investigations

Her laboratory investigations revealed $\beta$-Hcg to be 39.8, haemoglobin was 10.7 and white blood cell count to be 9600 . Urine analysis was within normal limits. Ultrasonography revealed normal uterus with endometrial thickness of $4 \mathrm{~mm}$. There was a presence of cystic mass in right adnexa of size $9.9 \times 8.5 \mathrm{~cm}$ [Fig 1(a)] along with heterogenous area of $5 \times 8.2 \mathrm{~cm}$ [Fig 1(b)] with no vascularity and surrounding free fluid. Right ovary could not be seen separate from this. Left ovary was normally seen in its place. [Fig 2] A provisional diagnosis of chronic ectopic versus ovarian torsion was made as ultrasound findings were indeterminate and her urine pregnancy test was positive urine.
Figure 1 (a) Transvaginal ultrasound demonstrating: $9.9 \times 8.5 \mathrm{~cm}$ cystic lesion in right adnexa (black arrow)

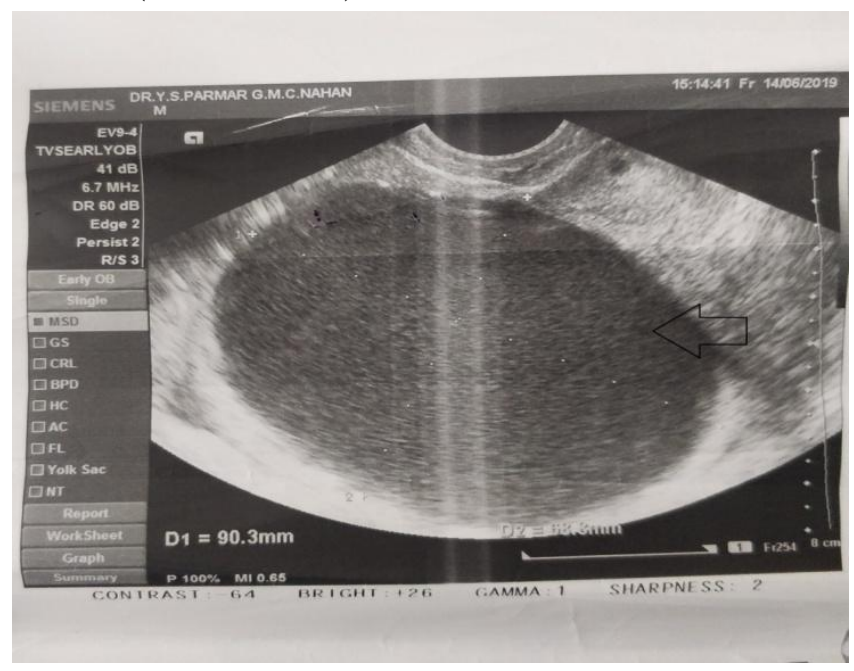

Figure 1(b) Transvaginal ultrasound demonstrating: $5 \times 8.2 \mathrm{~cm}$ heterogenous area (black arrow) along with cystic lesion seen in right adnexa with surrounding free fluid (red arrows)

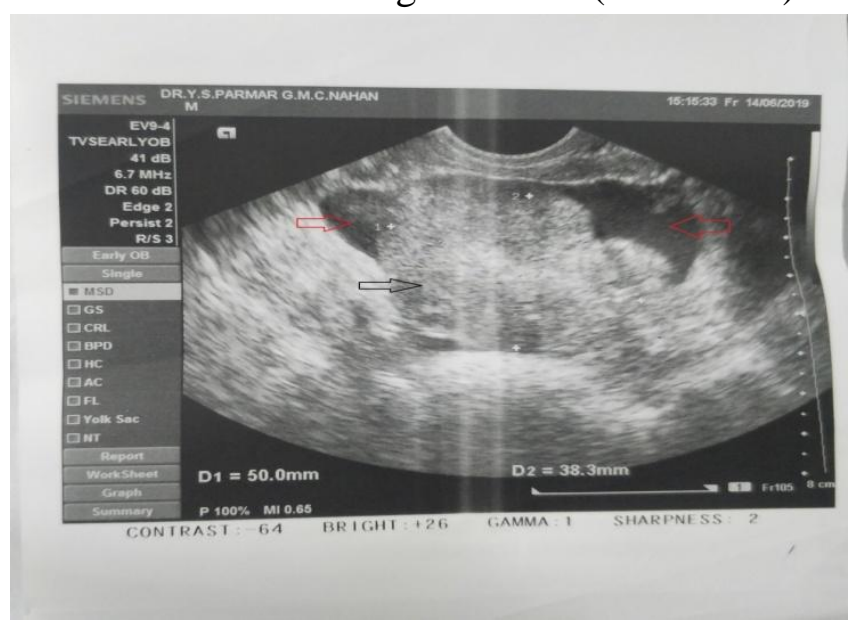

Figure 2: Transvaginal ultrasound demonstrating normal left ovary

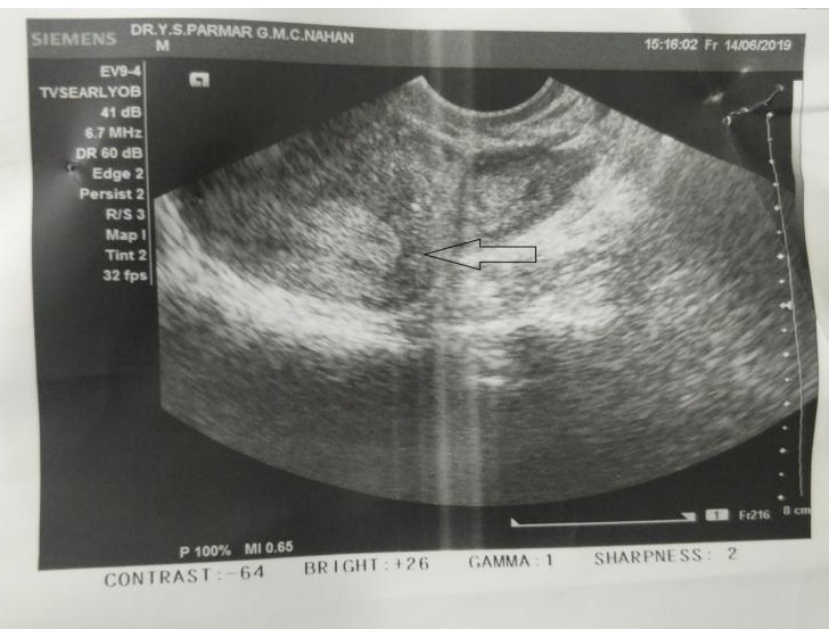




\section{Treatment}

Patient was subjected to exploratory laparotomy and a midline infraumbilical incision was given under regional anaesthesia. Intra operatively 10 $\mathrm{cm}$ enlarged, cyanotic and congested right fallopian tube was seen along with $5 \mathrm{~cm}$ completely necrotic torsed right ovary [Fig 3]. Haemorrhage into the fallopian tube made fimbria to stretch across its surface [Fig 4]. There was 100 $\mathrm{ml}$ of haemoperitoneum. Uterus [Fig 3], left tube and left ovary was within normal limits. Investigation of vascular supply to these organs revealed torsion. Detorsion was done but there were no signs of reperfusion [Fig4] so right salpingoopherectomy was performed and the specimen was sent to pathology for further examination.

Figure 3: Intraoperative image showing distended fallopian tube (green arrow) with stretched fimbria (orange arrow) with necrotic and torsed right ovary (yellow arrow). Note is also made of normal uterus (black arrow). P.S. Note the ovary lies anterior to fallopian tube due to torsion.

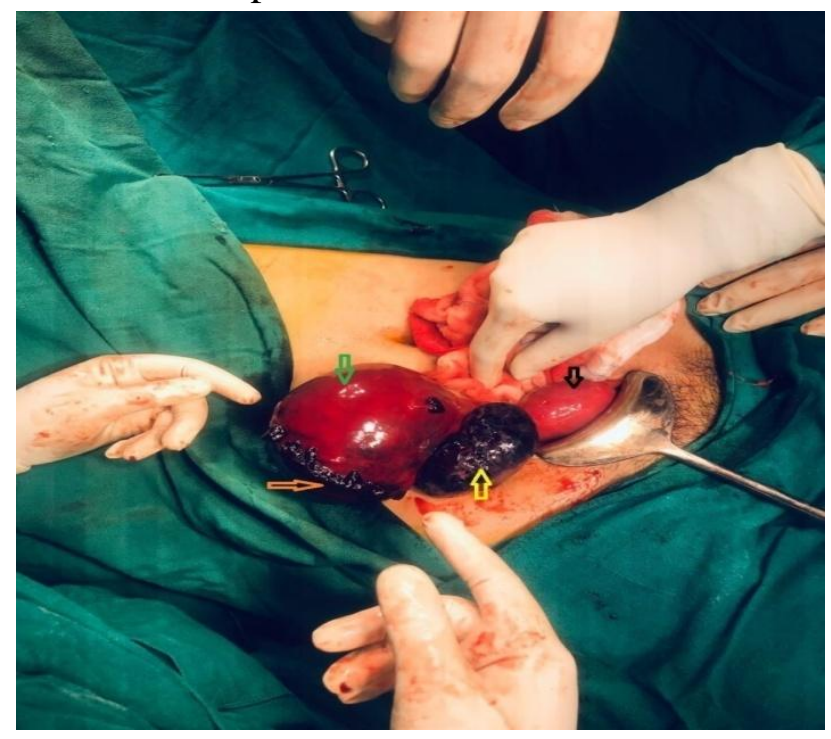

Figure 4. Per-operative image taken after detorsion with ovary showing no signs of reperfusion (green arrow). P.S. Note ovary lying posterior to fallopian tube.

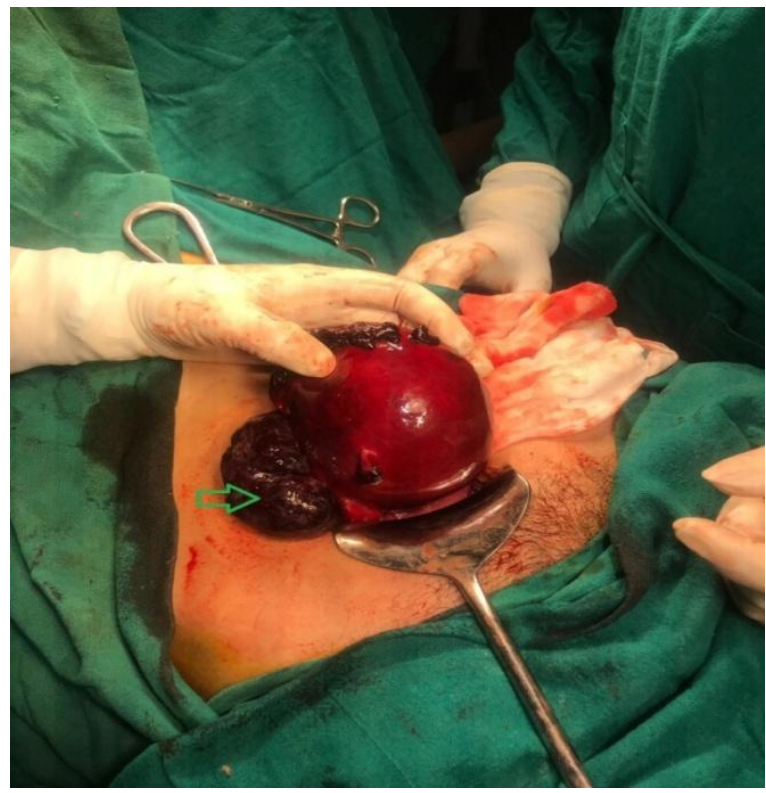

\section{Outcome and follow up}

The patient had a good post-operative recovery and was discharged on fifth postoperative day on micronized progesterone. Histopathological examination was consistent with findings of adnexal torsion showing extensive areas of haemorrhage and necrosis with no viable cyst lining seen. Patient followed up after 1 month of surgery and follow up ultrasound done revealed a viable fetus of crown rump length 6 weeks 4 days. The patient is presently 14 weeks pregnant and is on regular antenatal follow up with us.

\section{Discussion}

Adnexal torsion can occur at any age but is more common during reproductive years with greatest incidence between 20 to 30 years of age. ${ }^{4}$ Also, $70 \%$ of cases occur on the right side, as seen in our case which may be explained by the presence of sigmoid colon on left side which limit the mobility of adnexa and hypothetized long pelvic pedicle on right side. ${ }^{5,6}$ Risk factors for ovarian torsion include pregnancy, ovarian stimulation and cystic enlargement of the ovaries such as mature cystic teratoma, haemorrhagic cyst and serous cyst adenomas. Around $17-20 \%$ of cases are seen in 
pregnant women ${ }^{7,8,9}$ and the presence of ovarian mass more than $5 \mathrm{~cm}$ make ovary prone for torsion. In present case pregnancy and ovarian cyst were the two risk factors present.

Ovarian cysts are managed conservatively in pregnancy if diagnosed in first trimester and are surgically intervened between 16 to 28 weeks. However, in cases of torsion or ruptured ovarian cyst immediate surgical intervention is warranted. ${ }^{10}$ Ovarian torsion is most commonly seen in first trimester, less frequently in second and rarely in third trimester. ${ }^{1}$ This patient also presented to us in early first trimester. Most of the patients present with sudden onset of abdominal pain or long periods of intermittent pain along with nausea and vomiting. ${ }^{11,12,13}$ Leukocytosis and non-menstrual vaginal bleeding are the other features present in cases of torsion. The diagnosis of ovarian torsion is challenging because many signs and symptoms accompanying torsion can also be seen in other gynaecological conditions like pelvic inflammatory disease, ectopic pregnancy, appendicitis, tubo-ovarian abscess and ruptured ovarian cyst. Thus a high index of suspicion is needed because torsion needs immediate surgical intervention to avoid ischaemia and subsequent loss of ovarian and tubal function.

Pelvic ultrasound is considered as optimal imaging modality for diagnosis of torsion because it can evaluate ovarian anatomy as well as perfusion and is also accessible, non-invasive and cost effective. However, it is limited by interoperator variability and its limited use for diagnosing non-gynaecological etiologies of pain. The sensitivity of ultrasound for diagnosing torsion is sub-optimal with false negative rate of $45-61 \% .^{12,14,15}$ In addition, Doppler is considered to be relatively specific but disappointingly insensitive. ${ }^{16}$ Comparison with asymptomatic contralateral side is typically very useful. The findings confirmatory for torsion includes presence of twisted vascular pedicle on grey scale US and the whirlpool sign on color Doppler sonography which is basically circular or coiled vessels seen at the level or twist. ${ }^{17,18}$ In present case ultrasound was indeterminate for diagnosis of torsion because vascular pedicle was not seen and the haemorrhage inside the fallopian tube had the same appearance as that of the fluid surrounding the ovary which made it difficult to be identified as a separate cystic structure. Also, there was neither any identifiable cyst inside the ovary nor any peripheral follicles so it appeared as an heterogenous area on the ultrasound. In addition, presence of positive urine pregnancy test made us to think on lines of ectopic pregnancy though she had classical presentation.

Surgical management remains the cornerstone of treatment. Over the years various studies have shown that detorsion should be done for every case of irrespective of the appearance of ovary followed by more conservative approach of cystectomy. ${ }^{3,19,20}$ If needed a second surgery can be performed 4 to 6 weeks later once edema and haemorrhage has been resolved. In our case after untwisting the vascular pedicle no reperfusion was seen so right salpingoopherectomy was done.

\section{Conclusion}

Diagnosis of ovarian torsion continues to be a difficult task requiring awareness and a high degree of suspicion. An early laparoscopy/ laparotomy should be considered in order to avoid making an inaccurate diagnosis that may significantly impact on a woman's future fertility.

\section{References}

1. Hibbard LT: Adnexal torsion. Am J Obstet Gynecol. 1985, 152: 456-461.

2. Albayram F, Hamper UM. Ovarian and adnexal torsion: spectrum of sonographic findings with pathologic correlation. J Ultrasound Med 2001;20(10):1083-1089.

3. Breech LL, Hillard PJ. Adnexal torsion in pediatric and adolescent girls. Curr Opin Obstet Gynecol 2005;17(5):483-489.

4. Hata K, Hata T, Senoh D, et al. Change in ovarian arterial compliance during the human menstrual cycle assessed by 
Doppler ultrasound. Br J Obstet Gynaecol 1990;97(2):163-166.

5. Hall DA, McCarthy KA, Kopans DB. Sonographic visualization of the normal post-menopausal ovary. J Ultrasound Med 1986;5(1):9-11.

6. Ritchie WG. Sonographic evaluation of normal and induced ovulation. Radiology 1986;161(1):1-10.

7. Bouguizane $\mathrm{S}$, Bibi $\mathrm{H}$, Farhat $\mathrm{Y}$, et al. Adnexal torsion: a report of 135 cases. J Gynecol Obstet Biol Reprod 2003;32(6):535-540.

8. Stark JE, Siegel MJ. Ovarian torsion in prepubertal and pubertal girls: sonographic findings. AJR Am J Roentgenol 1994;163(6):1479-1482.

9. Graif M, Itzchak Y. Sonographic evaluation of ovarian torsion in childhood and adolescence. AJR Am J Roentgenol 1988;150(3):647-649.

10. Yen CF, Lin SL, Murk W, Wang CJ, Lee CL, Soong YK, Arici A: Risk analysis of torsion and malignancy for adnexal mases during pregnancy. Fertil Steril. 2009, 91 (5): 1895-902.

11. Kokoska ER, Keller MS, Weber TR. Acute ovarian torsion in children. Am J Surg. 2000 Dec;180(6):462-5.

12. Oltmann SC, Fischer A, Barber R, Huang R, Hicks B, Garcia N. Cannot exclude torsion--a 15-year review. J Pediatr Surg. 2009 Jun;44(6):1212-6; discussion 1217.

13. Rousseau V, Massicot R, Darwish AA, Sauvat F, Emond S, Thibaud E, NihoulFekete C. Emergency management and conservative surgery of ovarian torsion in children: a report of 40 cases. $J$ Pediatr Adolesc Gynecol. 2008 Aug;21(4):201-6.

14. Hiller N, Appelbaum L, Simanovsky N, Lev-Sagi A, Aharoni D, Sella T. CT features of adnexal torsion. AJR 2007;189:124-9.
15. Hasson J, Tsafrir Z, Azem F, et al. Comparison of adnexal torsion between pregnant and nonpregnant women. Am J Obstet Gynecol 2010;202:536.e1-6.

16. Bar-On S, Mashiach R, Stockheim D, et al. Emergency laparoscopy for suspected ovarian torsion: are we too hasty to operate? Fertil Steril 2010;93:2012-5.

17. Lee EJ, Kwon HC, Joo HJ, Suh JH, Fleischer AC. Diagnosis of ovarian torsion with color Doppler sonography: depiction of twisted vascular pedicle Ultrasound Med 1998;17(2):83-89.

18. Vijayaraghavan SB. Sonographic whirlpool sign in ovarian torsion. $\mathbf{J}$ Ultrasound Med 2004;23(12):1643-1649.

19. Oelsner G, Shashar D. Adnexal torsion. Clin Obstet Gynecol 2006;49(3):459-463.

20. Rha SE, Byun JY, Jung SE, et al. CT and MR imaging features of adnexal torsion. Radio Graphics 2002;22(2):283-294. 